\title{
O cinema como linguagem no ensino de ciências
}

Alcione José Alves Bueno alcioneab10@gmail.com https://orcid.org/0000-0002-7058-887X Universidade Estadual de Ponta Grossa (UEPG), Ponta Grossa, Paraná, Brasil

\section{Silvio Luiz Rutz da Silva}

slrutz@gmail.com

https://orcid.org/0000-0003-1859901 Universidade Estadual de Ponta Grossa (UEPG), Ponta Grossa, Paraná, Brasil

\section{RESUMO}

Pensando no ensino de ciências não apenas como produto científico, mas também e fundamentalmente, como produto sócio cultural, este trabalho teve como objetivo apresentar uma reflexão sobre a utilização do cinema enquanto linguagem no Ensino de Ciências. Para isto, apresenta historicamente o processo formativo das ciências enquanto disciplina curricular da educação básica, bem com aproxima o ensino de ciências da linguagem cinematográfica, a qual denomina-se de linguagem audiovisual. De modo a facilitar o processo de leitura de uma obra fílmica, no decorrer deste trabalho, destaca-se a necessidade da alfabetização audiovisual, tanto em termos cognitivos, quanto em termos técnicos dos métodos utilizados na composição de um filme. Como resultados iniciais, enfatiza-se a necessidade de utilização deste tipo de recurso na sala de aula, tendo em vista que fazem parte do cotidiano do aluno e não devem ser menosprezadas. Porém, este estudo não se deteve em ilustrar os métodos construtivos de uma produção fílmica, mas apontar caminhos para o professor, que o levem a perceber que esses mesmos métodos construtivos apresentam características que facilitam a leitura de uma obra fílmica, e devem estar presentes em sua pedagogia, quando objetivarem sensibilizar os alunos para o conhecimento, tendo filmes como objeto mediador.

PALAVRAS-CHAVE: Ensino de ciências. Filmes. Linguagem audiovisual. 


\section{INTRODUÇÃO}

O ensino de Ciências é relativamente recente no Brasil. No ensino fundamental, somente se consolidou por meio da disciplina de Ciências, com a promulgação da Lei de Diretrizes e Bases da Educação, no 4.024, de 20 de dezembro de 1961, tornando obrigatório naquela época para todos os níveis do antigo ensino ginasial (TRIVELATO; SILVA, 2011). Deste modo, é preciso considerálo ainda em estado de construção e significação.

No âmbito da pesquisa, o ensino de Ciências vem se desenvolvendo expressivamente no Brasil, tendo uma maior abrangência a partir dos anos de 1970, juntamente com o aumento dos cursos de pós-graduação na área de ensino e educação em Ciências (MEGID NETO, 1999).

O ensino de Ciências deve ser pensado não somente como produto científico, mas especialmente como produto social, tanto no contexto da sua gênese e produção, como no âmbito educacional. Nesse caso, o conhecimento científico vem sendo explorado por meio de conteúdos curriculares, em que o conhecimento científico é transposto e discutido em disciplinas, sendo denominada por FreireMaia (2000) como ciência-produto, derivada da ciência-processo, atividade científica desenvolvida em forma de pesquisa e divulgada pelos cientistas.

Conforme aponta o documento de Orientação Curricular de Ciências para as escolas do Estado do Paraná (PARANÁ, 2008), o conhecimento científico mediado para o contexto escolar, no entendimento de que esse conhecimento (ciênciaproduto) é adequado para a escola básica, sofre um processo de didatização, mas não se confunde com o conhecimento cotidiano. Nesse sentido, os conhecimentos científicos escolares selecionados para serem ensinados na disciplina de Ciências têm origem nos modelos explicativos construídos a partir da investigação da natureza, de fenômenos complexos e situações problemas atrelados com a cultura, a tecnologia, a sociedade e os saberes tradicionais.

É notória a presença das novas tecnologias em todas as esferas da sociedade. Deste modo, algo que é tão inseparável do mundo moderno - como é o caso das tecnologias midiáticas - pode e deve ser utilizado como um recurso didático para o ensino de Ciências.

A utilização de tecnologias no campo educacional teve início nos Estados Unidos, a partir dos anos 40. A primeira disciplina curricular acadêmica voltada para a utilização das então novas tecnologias em sala de aula surgiu na Universidade de Indiana em 1946. Com foco nos recursos audiovisuais, a disciplina tinha caráter formativo e desenvolveu o primeiro campo específico da tecnologia na educação (ALTOÉ; SILVA, 2005). Já a década de 70 foi o ponto de partida para o uso da informática como ferramenta educacional, com vistas ao ensino assistido por computador.

No Brasil, o uso das tecnologias como abordagens pedagógicas, esteve voltado inicialmente para o Educação a Distância (EaD), com cursos de capacitação e formação continuada. Vídeos tutoriais, programas da TV Cultura e outros como o Telecurso, que ainda está em funcionamento, são exemplos de tecnologias que foram aplicadas ao ensino brasileiro ainda no século XX. Considerados um progresso, apesar de apresentarem uma abordagem mecanizada inserida num 
contexto de ensino tradicional, evoluindo apenas para um ensino tradicional mediado pelas tecnologias.

Neste sentido, Kenski (2003) alerta que a potencialidade das Tecnologias Digitais de Informação e Comunicação (TDIC), não está apenas em sua aplicabilidade no ensino, mas sim, na forma como é utilizada, para que não sirva apenas como distração, mas promova o processo de ensino-aprendizagem, mediado pelo professor, que deve lançar seu olhar para os aprendizes que são os autores deste processo. Mesmo assim, ela salienta que "a comunicação e a educação vivem momentos de efervescência” (KENSKI, 2008, p. 662), e enfatiza a necessidade da incorporação das TDIC no ensino, pois estão presentes no cotidiano da sociedade, e com isso é possível experenciar novos aprendizados, partindo da própria realidade.

Norteados pelo exposto, é preciso considerar que "a ação educacional consiste justamente em auxiliar o aprendiz, de modo que a construção de conhecimento possa acontecer" (VALENTE, 2014, p. 144). Torna-se essencial ao ensino promover esse processo de construção de conhecimento, levando o aluno a vislumbrar a potencialidade do que está aprendendo, partindo de sua realidade, e como isso será significativo em sua realidade. Ensinar por ensinar não basta, é necessário que este processo tenha um objetivo real, tendo sempre o aprendiz como centro.

Nas palavras de Valente (2014):

[...] a questão fundamental no processo educacional é saber como prover a informação, de modo que ela possa ser interpretada pelo aprendiz que passa a entender quais ações ele deve realizar para que a informação seja convertida em conhecimento. [...] Se a informação obtida não é posta em uso, se ela não é trabalhada pelo professor, não há nenhuma maneira de estarmos seguros de que o aluno compreendeu o que está fazendo. Nesse caso, cabe ao educador suprir tais situações para que a construção do conhecimento ocorra (VALENTE, 2014, p. 144-145).

Esta mediação, pautada nas TDIC, é proposta por Valente a partir de alguns eixos: no uso da TDIC como simulador de fenômenos e no uso de narrativas digitais (VALENTE, 2014). Enquanto simulador, sua potencialidade se encontra na capacidade das TDIC em animar objetos na tela, bem como a de simular fenômenos que não poderiam ser elaborados no mundo real, como ocorre em conteúdos curriculares da disciplina de ciências. Enquanto uso de narrativas digitais, o autor propõe que as formas tradicionais de narrativas, como a oral e a escrita, podem ser produzidas pelas TDIC, contribuindo "para que essa atividade seja muito mais rica e sofisticada do ponto de vista da representação do conhecimento e da aprendizagem" (VALENTE, 2014, p. 153).

Os recursos digitais aprimorados para o ensino, auxiliam o processo de ensinoaprendizagem, ao conter elementos que incentivem a relação aluno-professorconhecimento. Por conter mecanismos capazes de proporcionarem atividades mais dinâmicas, com maior apeno sonoro e imagético, propiciam um contato mais imediato e profundo com o objeto de estudo. 


\section{CINEMA E ENSINO DE CIÊNCIAS}

O cinema teve seu início ainda no século XIX, quando inventores como Thomas Edison, Charles F. Jenkins e os irmãos Lumiére vislumbram a potencialidade e fizeram avanços na produção de imagens em movimento (RODRIGUES, 2010). Enquanto inventores do cinema, aos irmãos Lumiére é dado o crédito de execução da primeira exibição pública, no ano de 1985 , embora não tenham sidos os pioneiros a projetar imagens em movimento. Para Santos (2013, p. 63) "os progressos tecnológicos no século XIX geraram transformações na vida da sociedade. Tecnologias como o telefone, o rádio, o telégrafo, o cinematógrafo, a eletricidade, os carros, entre outros, aproximaram pessoas e encurtaram distâncias entre países [...]". Com isso, propiciaram o acesso e, em pouco tempo, o uso se tornou generalizado.

Em território nacional, a primeira sessão de cinema aconteceu em 1896. No ano de 1897 foi inaugurada a primeira sala regular para a exibição de filmes, deixando de ser entretenimento das ruas e passando para as salas de teatro. Tendo grande aceitação no Brasil, o cinema, logo foi apropriado para a educação, devido a sua grande potencialidade para o ensino. No âmbito escolar, essa relação ganhou intensidade a partir do século XX, quando setores sociais ligados à escola nova e à Igreja Católica apoiaram esses projetos por entenderem que havia uma necessidade de rompimento com as práticas pedagógicas usais até então (SANTOS, 2013).

Com isso, nos primórdios no século XX, já haviam discussões amplamente difundidas sobre o cinema e a educação brasileira, vendo-se nesta ligação uma grande abertura para o ensino nacional (REIS JUNIOR, 2008). Seguindo esse ideal, Santos (2013, p. 66), aponta que "a forma como o espectador vê e lê as representações do mundo produzidas pelo cinema, as quais se articulam em imagens, sons, palavras e movimento (ilusão), o leva a construir interpretações por meio de contextos socioculturais". Para Carvalho (2007) os elementos que compõe uma produção fílmica permitem ao telespectador interpretar o mundo a partir do conjunto de sons e imagens que observa, estimulando reflexões críticas por parte dos aprendizes.

Como Chaves (1999) aponta, nem todas as tecnologias são significativas para a educação, entretanto, aquelas que estimulam o aluno certamente devem ser utilizadas no processo de ensino-aprendizagem. É neste viés que a utilização de filmes comerciais como recurso pedagógico pode ser viável no âmbito educacional. Isto se alicerça na Lei 13.006/14 que normatiza políticas públicas que defendem a utilização do uso de filmes na escola "seja de leitura e análise de produções fílmicas nacionais, seja da produção expandida, alternativa, independente da comunidade escolar e do seu entorno" (FRESQUET, 2015, p. 30).

Mas vale ressaltar que, "os filmes não são uma produção da pedagogia ou da didática, pois, diferentemente, são produzidos dentro de um projeto artístico, cultural e de mercado. Se chega à escola é porque esta os didatiza" (BORBA, 2015, p. 30), quando os utiliza como recurso didático.

Entendendo que o uso de filmes comerciais como novas tecnologias na educação trata-se de um processo de sensibilização educacional, é preciso, por parte do professor, mediar sua utilização, tendo em vista que seu uso deve estar atrelado ao conteúdo proposto e não sirva apenas como tapa buracos (CYSNEIROS, 
2010). Dessa forma, "o professor atua como um mediador da leitura do filme em sala de aula e, com vistas a promover a fruição e também uma análise mais eficiente desse gênero" (THIEL; THIEL, 2009, p. 13). Portanto, cabe ao professor o papel de despertar no aluno a curiosidade pelo filme proposto, as ideias contidas na tematização e os elementos básicos presentes na produção audiovisual que promovam o ensino e a aprendizagem.

Desse modo, é preciso considerar que "[...] o filme é um recurso pedagógico mediador que possibilita subsidiar o ensino por meio da problematização em diferentes conteúdos relacionados às Ciências Naturais, por meio do diálogo, das diferentes disciplinas e do conhecimento escolar" (SANTOS, 2013, p. 67). Nesse sentido, abordagens educacionais com este engendramento propiciam o enfoque a diversas dimensões, ao relacionar questões históricas, sociais, culturais e etc. aos conteúdos curriculares estruturantes.

Conforme aponta Duarte (2009, p. 16) "ver filmes é uma prática social tão importante, do ponto de vista da formação cultural e educacional das pessoas, quanto a leitura de obras literárias, filosóficas, sociológicas e tantas mais", pois os filmes têm a capacidade de despertar nossas sensibilidades. Como apontam diversos autores (PIMENTA, 1995; NAPOLITANO, 2003; ARROIO; GIORDAN, 2006; CALASANS; LEE, 2008), a junção de distintas linguagens, seja na forma de grafia, imagem ou som, provocam sensações e recepções unificadas, gerando e provocando uma facilitação na acepção da mensagem que se quer transmitir.

Uma das necessidades do ensino de Ciências é a observação, a experimentação e vislumbramento de como ocorrem os processos naturais. Com isso a utilização de filmes lança olhares para além do imaginário do aprendiz, pois o conduz à uma representação audiovisual dos processos ocorridos na natureza. Não se tem a pretensão de defender a autonomia dos filmes frente ao conhecimento, compreendendo que sozinho os resultados podem ser falíveis, mas:

[...] diferentemente dos métodos clássicos, o universo midiático cria possibilidades de aprendizagens estimulantes a seus espectadores, potencializando o processo de ensino-aprendizado ao passo que a entrada dessas novas tecnologias facilita a criação de novos projetos pedagógicos e trocas interindividuais. Não se pretende dizer que o filme pode substituir o contato direto que um aluno deve ter com o objeto estudado conseguido por meio dessas experiências, por exemplo. Apenas é possível perceber que existem formas diversificadas de interação uma vez que, com o auxílio do filme, é possível trazer exemplificações visuais de situações que os alunos não teriam oportunidade de presenciar nas aulas, o que torna o filme um recurso pedagógico de muita eficiência (CARRERA, 2012, p. 46).

Com base nisso, percebe-se que as informações audiovisuais abrem novas possibilidades para o ensino-aprendizagem, propondo abordagens que superem o dito ensino tradicional e promovam o ensino nacional tão deficitário. Defende-se o uso de filmes na medida em que atuem como potencializadores do ensino, devido a rica presença de saberes científicos que tematizam. Importa focar não apenas nos filmes educativos, mas também e principalmente nos filmes ditos comerciais, que não foram criados sob uma abordagem pedagógica, mas que podem contribuir ricamente para a educação por suas características lúdicas e proximidade que promovem com a realidade dos alunos. 


\section{ALFABETIZAÇÃO AUDIOVISUAL}

É fato que o ensino dito tradicional pode ser considerado insatisfatório para uma alfabetização científica atualmente. Entendendo a diversidade sociocultural em que os alunos se encontram, é necessário vislumbrar mecanismos que contemplem novas formas de alfabetização e favoreçam a aprendizagem.

Com a promulgação da Lei de Diretrizes e Bases da Educação Nacional (LDB), no 9.394/96 (BRASIL, 1996), foram definidos novos modelos de aprendizagem e proposto que estas novas abordagens estivessem presentes em sala de aula. A LDB apresenta cinco novos tipos de alfabetização que seguem:

a) Alfabetização em Tecnologia da Informação e Comunicação (TIC).

b) Alfabetização Tecnológica.

c) Alfabetização em Informação.

d) Alfabetização em Mídia.

e) Alfabetização Visual.

Embasados por esta orientação, defendemos uma modalidade que não aparece nas LDB da Educação, mas que deve ser considerada atualmente, pois apresenta grande repercussão, que é a Alfabetização Audiovisual, que "[...] referese a toda a forma de comunicação sintética destinada a ser percebida ao mesmo tempo pelo olho e pelo ouvido" (LENCASTRE; CHAVES, 2007, p. 1164). Pois, defendemos a utilização do cinema em sala de aula como recurso facilitador do ensino e promotor de saberes.

Partindo da Alfabetização visual, temos dois tipos de linguagens: a visual que além de ser atemporal é perceptível no espaço; e a linguagem áudio que apresenta características temporais, mas nenhuma dimensão espacial visível (LENCASTRE; CHAVES, 2007). A junção destas, formam a linguagem audiovisual, que se apresenta integrada em tempo e espaço, sincronizando a comunicação acústica com a visual.

\section{A LINGUAGEM VISUAL}

É fato que as sociedades demonstram preferência por informações visuais, devido à grande carga de informações deste tipo, que estão presentes em seu dia a dia. Estamos repletos de informações deste tipo, pois vivemos numa sociedade que as utiliza frequentemente, como meio de publicidade e informação.

Dondis (2003), embora considere que existe uma diferença entre ver e entender, afirma que a visão supera eloquentemente os outros sentidos. Ainda enfatiza que "ver é uma experiência direta, e a utilização de dados visuais para transmitir informações representa a máxima aproximação que podemos obter com relação à verdadeira natureza da realidade" (DONDIS, 2003, p.7). Que pelo seu contato direto permite uma leitura imediata do objeto.

Durante o processo evolutivo, a imagem consagrou-se como linguagem inicial da humanidade, como pode ser observado pelas representações deixadas pelo homem primitivo, e que hoje denominamos como arte rupestre. 


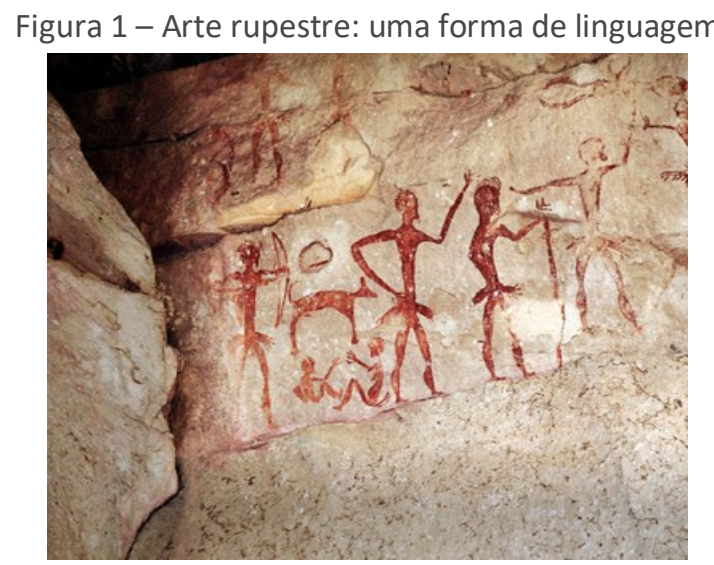

Fonte: Mundo Educação (2012).

Para Leite (1998), bem antes de existir a linguagem escrita, falada, e até outras tecnologias que permitiam capturar momentos, como as câmeras fotográficas, por exemplo, as expressões artísticas em paredes de caverna (Figura 1) e tantos outros locais que se apresentam, configuram uma forma de inteligência da humanidade, bem como minucias de organizações sociais e culturais.

Se na pré-história as representações eram feitas em paredes de cavernas, com o advento da idade moderna as representações e aplicações de imagens foram progressivamente modificando-se, exigindo cada vez mais de seus artistas. Nesse processo, também as técnicas de pintura se aperfeiçoaram, saindo das paredes das cavernas, e utilizando materiais mais sofisticados como telas e tintas a óleo. $\mathrm{Na}$ idade moderna, sobressaem grandes artistas como Michelangelo Buonarroti (1475-1564), Rafaello Botticini (1474-1520), Leonardo da Vinci (1452-1519), dentre tantos mais, que tiveram grande influência no movimento chamado Renascimento.

E se, nas sociedades antigas, as informações visuais eram a única forma de comunicação, precisamos perceber que na atualidade, tendo em vista a gama de informações visuais que fazem parte de nosso contexto, a leitura e intepretação dessas informações, devem estar atreladas a nossa percepção.

Dessa forma, "é necessário que o trabalho possua os elementos de comunicação visual (harmoniosamente trabalhados) para que o receptor tenha despertada sua sensibilidade, e para que se obtenha o efeito desejado" (VAZ; ANDRADE; SIQUEIRA, 2009, p. 599). Cabe ao ilustrador, direcionar aonde quer que o receptor olhe, pois, os elementos compositivos permitem chamar a atenção do observador e com isso levá-lo a entender a informação que se quer passar.

Para entender uma informação visual, é preciso considerar a sua estruturação e os elementos que a compõem, como o ponto, dimensão, movimento, tom, textura, cor, direção, proporção e forma. Entendendo estes elementos compositivos é possível compreender mais facilmente uma mensagem visual.

O equilíbrio na percepção visual

Uma das características mais marcantes da percepção humana, seja ela física ou psicológica, é a necessidade de equilíbrio que se expressa em todos os seus atos 
(DONDIS, 2003). Alguns pesquisadores (VAZ; ANDRADE; SIQUEIRA, 2009), também discutem sobre essa constante inconsciente do equilíbrio sobre a percepção humana, por considerar que todo ser busca um equilíbrio no que observa, mesmo que não entenda seus conceitos e não saiba sob os elementos que compõe uma informação visual.

Em Dondis (2003, p. 32) encontramos referências ao equilíbrio por considerar que "[...] enquanto todos os padrões visuais têm um certo centro de gravidade que pode ser tecnicamente calculável, nenhum método de calcular é tão rápido, exato e automático quanto o senso intuitivo de equilíbrio inerente às percepções do homem". Assim, a relação básica do homem com seu entorno é resultado de um constructo horizontal-vertical que proporciona uma estabilidade à sua percepção.

Essa relação inconsciente e necessária de uma verticalidade, fortificada sobre uma base estável é expressa nos elementos que compõe a Figura 2a, assim como essa relação entre horizontalidade e verticalidade é ilustrada na Figura $2 b$, bem como uma relação de equilíbrio de uma composição com peso variável, é ilustrado na Figura 2c.

Figura 2 - Constante de Verticalidade formada inconscientemente pelos eixos visuais

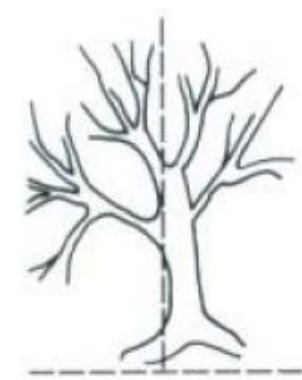

(a)

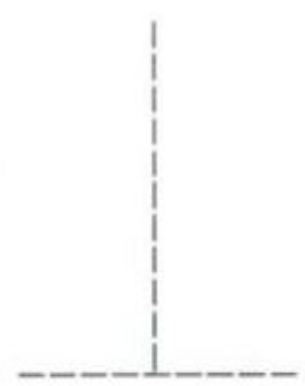

(b)

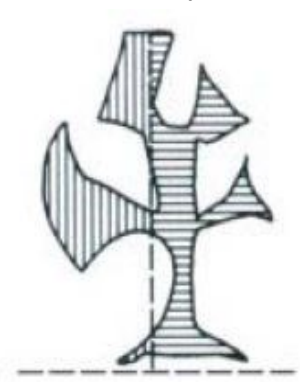

(c)

Fonte: Adaptado de Dondis (2003).

Partindo da imagem expressa, salienta-se que um processo de interpretação visual impõe a uma informação visual um eixo vertical, que se apoia sobre um eixo horizontal, propiciando um equilíbrio em uma leitura inicial. Para Dondis (2003, p. 33) esta forma de equilíbrio na composição imagética é "uma constante invisível". Trata-se de um conjunto de fatores que propiciam equilíbrio e norteiam a significação de uma informação visual de um eixo sentido inconsciente, no ato de ver.

Tensão e equilíbrio

Como foi mencionado acima, quando se tem o eixo vertical na percepção visual, busca-se a estabilidade, o equilíbrio. Dondis (2003, p. 35) salienta que "esse processo de ordenação, de reconhecimento intuitivo da regularidade ou de sua ausência, é inconsciente e não requer explicação ou verbalização". É inerente a percepção física e psicológica humana buscar estabilidade, e quando esta falta, causa desorientação.

Essa relação existente entre tensão e equilíbrio pode ser observada em qualquer mensagem visual. Segue um exemplo: 
Figura 3 - Relação entre tensão relativa e equilíbrio

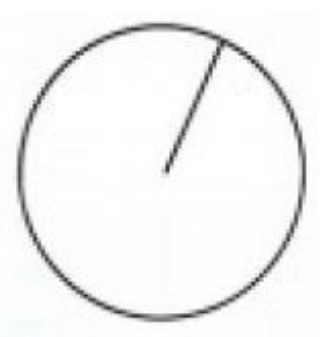

(a)

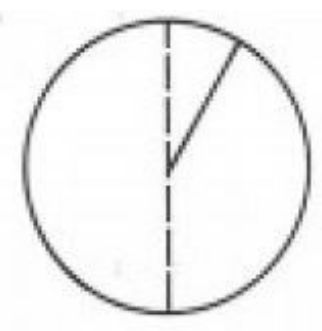

(b)

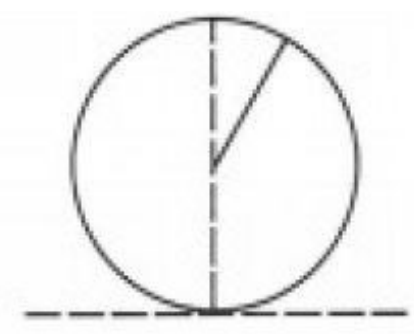

(c)

Fonte: Dondis (2003).

Na Figura 3 é possível observar uma relação entre tensão e equilíbrio. Como visto, na Figura 3a, o raio em ponta no interior de um círculo, apresenta uma tensão por não estar enquadrado no eixo visual invisível, gerando desiquilíbrio. Quando se acrescenta o eixo sentido vertical (Figura 3b), o raio, que é o elemento visível, é modificado. Este também se modifica quando se acrescenta o eixo sentido horizontal (Figura 3c).

Para Vaz, Andrade e Siqueira (2009, p. 600) “o que uma pessoa vê (percebe) não é apenas um arranjo de cores, formas e tamanhos, mas sim uma interação de tensões (forças psicológicas)". Pois, se utilizar dois círculos, como exemplo, postos lado a lado, um com o raio centrado e o outro não concordante (fora da zona de equilíbrio), certamente o que apresentasse desiquilíbrio chamaria mais atenção, por causar tensão na percepção visual sobre o objeto. Dessa forma, nas palavras de Dondis (2003, p. 36), "a tensão, ou sua ausência, é o primeiro fator compositivo que pode ser usado sintaticamente na busca do alfabetismo visual". Pois, inconscientemente, no campo visual, o observador busca um eixo sentido e quando não o encontra, entra em estado de desiquilíbrio (tensão), buscando responder os fatores que os causam.

Nivelamento e aguçamento

Embora a humanidade busque equilíbrio e normalidade, a novidade sempre é bem aceita quando traz surpresa positiva. Na composição visual, a estabilidade e a harmonia são dispares àquilo que é inesperado e que gera tensão (DONDIS, 2003). Na psicologia, essa oposição de elementos é denominada de nivelamento e aguçamento, e que foi voluntariamente, incorporado pelas artes visuais, para os elementos compositivos de uma mensagem visual.

Todos os elementos que se enquadram no eixo sentido harmoniosamente podem ser considerados como nivelados para a composição visual. Diferente disto, quando estão totalmente fora desse enquadramento, formado inconscientemente pela percepção visual, são chamados de aguçados. Entretanto, existe um terceiro caso, em que não se encontra nivelado e nem aguçado, mas sim em estado de ambiguidade, isto é, sua posição não está clara, tem como objetivo voluntário ou não, confundir o observador, pois "[...] a ambiguidade visual obscurece não apenas a intenção compositiva, mas também o significado" (DONDIS, 2003, p. 39). Em termos de composição, é indesejável uma ambiguidade visual, por confundir a visão. Nas composições visuais, seus elementos constituintes não devem de modo 
algum obscurecer a leitura e significado, mas sim criar harmonia, ou contrastar, causando tensão, repelir ou atrair, levando a percepção visual a procurar um campo visual harmonioso, criado pelo eixo sentido em equilíbrio.

\section{O CINEMA COMO LINGUAGEM}

Os documentos oficiais que norteiam os caminhos da educação brasileira a nível nacional são os Parâmetros Curriculares Nacionais (PCN). Eles defendem a busca por novas formas de propulsar o ensino-aprendizagem na educação básica, com estratégias que facilitem o processo de aproximação do aprendiz com o conhecimento (BRASIL, 2002).

Diante do cenário atual é possível perceber o papel desprestigiado da educação. É imprescindível vislumbrar novos ambientes e mecanismos que propiciem o processo de ensino-aprendizagem. Pensar em formas diferenciadas de se trabalhar o conteúdo escolar é uma das tarefas do professor diante desta sociedade da informação em que se inserem os alunos. É fato que a aprendizagem também ocorre em ambientes diversificados e principalmente por intermédio dos meios de comunicação, que bombardeiam os aprendizes com informações, nem sempre confiáveis. Se sabe mais do mundo real pelo modo como a televisão e os meios de comunicação o apresenta, os quais muitas vezes não abordam conhecimentos científicos, apenas senso comum e que nem sempre são corretos.

Neste viés, Alencar (2007, p. 15), enfatiza que a aprendizagem ocorre em ambientes transversais, "principalmente através dos meios de comunicação de massa, dentre eles o cinema. Nada melhor, então, do que aproveitar para educar e instruir jovens com as imagens, os sons e a linguagem cinematográfica como uma fonte a mais de conhecimento". E para educá-los para a leitura cinematográfica, é preciso compreender os elementos que estruturam a cinematografia e de que modo as vincular ao ensino. Pois, o cinema por si só não garante o ensino, mas mediado pelo professor, pode propiciar uma alfabetização científica por meio da linguagem que os filmes expressam. E esse papel de alfabetizar para o audiovisual cabe ao professor.

O cotidiano dos alunos é uma mistura de informações de diversos enquadramentos, sendo necessário instiga-lo a analisar tais informações, de um modo que não que não se torne apenas receptor do que lhe é transmitido, mas tenha a criticidade em construir um conhecimento elaborado, a partir daquilo que é exposto. Nesse sentido, nas palavras de Faria et al (2015, p. 647), "[...] na busca de diferentes modos de experimentar o mundo, pode-se utilizar a riqueza das várias formas de linguagem possíveis de serem inseridas no ambiente escolar [...]". Dentre essas, caracteriza-se os filmes como uma ferramenta de profunda riqueza para se atingir fins de ensino. Para Faria et al (2015), os filmes podem ainda se tornar instrumentos que auxiliem a ação pedagógica.

Mas ainda cabe salientar, como nos alerta Araújo (1987), "há um bom tempo, que [...] em matéria de cinema somos obrigatoriamente iniciantes: "compreendêlo" equivale a 'saber vê-lo', uma tarefa sempre inacabada, sempre renovada" (ARAÚJO, 1987, p. 13). É conciso ainda em afirmar que "[...] quando o cinema não for mais capaz de provocar surpresa e espanto, quando alguns filmes não levarem à perplexidade o espectador, certamente alguma coisa estará errada: ou com o 
cinema ou com o espectador" (ARAÚJO, 1987, p.13). Com isso, defende a inovação contínua que os filmes propiciam juntamente com sua contribuição sociocultural, que corroboram por ilustrar as realidades vivenciadas.

Nos trabalhos de diversos autores (SILVA, 2000; NAPOLITANO, 2003; SETTON, 2004; CARRERA, 2012, FARIA et al, 2015), é possível encontrar referências à defesa da utilização de recursos audiovisuais, com maior atenção aos filmes como recursos facilitadores do ensino. Isso se dá, quando os filmes contêm ferramentas que cativam o telespectador em seu enredo, também são quando estruturados de forma coerente e ainda, quando o telespectador é capaz de lê-lo criticamente.

É preciso compreender que os filmes, quando não são do tipo cinema mudo, unem imagem e som, propiciando aos telespectadores uma sensação sinestésica de mensagens. "O filme tem a capacidade de juntar elementos visuais e sonoros de modo dinâmico criando uma recepção unificada pelos sentidos humanos gerando, assim, envolvimento com os personagens e com as emoções portadoras de significados" (CARRERA, 2012, p. 38). Mas cabe salientar que mesmo que esta reflexão tenha sido norteada pelos pressupostos da alfabetização audiovisual, não é objetivo defini-la conceitualmente e nem estabelecer uma gramática para a leitura fílmica, por meio de suas imagens e narrativas. O foco é ilustrar que os elementos constituintes desse tipo de produção podem influenciar na compreensão de seu enredo e como essas informações podem favorecer a aprendizagem quando usados como recursos pedagógicos.

A partir do exposto, "[...] é possível oferecer aos alunos mais oportunidades de contextualização dos conteúdos com filmes, bem como apresentar o cinema como uma forma de linguagem utilizada para contar os fatos, mesmo quando são fictícios" (FARIA et al, 2015, p. 648). Mas atentando-se sempre aos seus elementos constituintes, pois a leitura de um filme deve considerar sua construção, tanto objetiva quanto subjetiva.

E como enfatiza Carrera (2012), a constituição de uma sequência fílmica envolve a junção de vários fatores:

Elementos como efeito de luz, som, ritmo de cortes e ângulo da cena podem mudar o percurso de uma narração reproduzindo sensações a serem captadas pelos espectadores e, portanto, compartilhadas de forma afetiva com a mensagem exposta. Para conseguir o equilíbrio entre estes elementos ele conta com uma coerência em sua linguagem que é denominada como linguagem audiovisual. (CARERRA, 2012, p. 38)

A partir do exposto nessa subseção, acredita-se necessário dialogar a respeito da linguagem do cinema, pois é impossível falar em cinema enquanto linguagem, sem considerar os constituintes de sua produção.

Nas artes visuais, cores quentes, são aquelas que apresentam tonalidades que vão do vermelho ao amarelo, dando um destaque maior ao objeto, já as frias, proporcionam a sensação de mansidão e seriedade, em uma escala que vai do azul ao verde. Quando usadas corretamente, estas cores trazem sensações de alegria ou tristeza, podendo também representar suspense, entre outras características. 
Carrera (2012), afirma que "é tentando representar a luminosidade ou a falta dela, que se busca alcançar expressividade criando climas temporais e psicológicos, com diferentes gradações de luz e sombra que podem ser reproduzidos em estúdios ou por computação". (CARRERA, 2012, p. 39). A luminosidade pode alterar completamente como se vê um objeto, proporcionando sensações diversificadas.

Plano

Em uma construção fílmica, os planos podem ser considerados como espaços entre dois cortes, variando de acordo com o fim a que se destinam. Podem apresentar diferentes ângulos ou focalizar um único personagem. Cada plano é classificado devido a sua duração, visto que cada cena em um filme, desperta diferentes sensações no telespectador. Esta classificação está expressa na Figura 4.

Figura 4 - Planos em uma composição fílmica

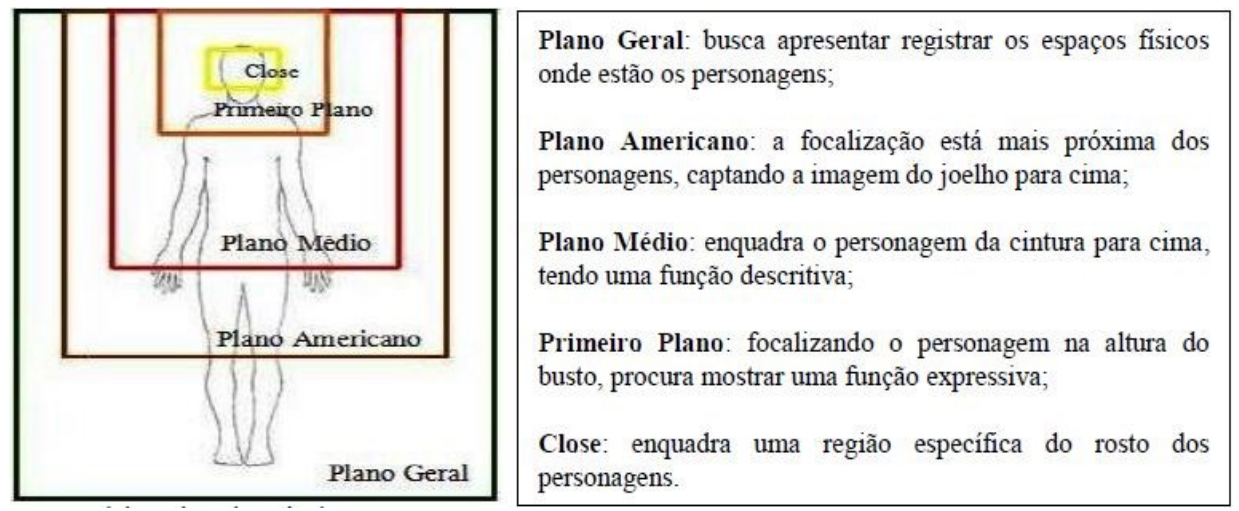

Fonte: Sousa (2012, p. 289).

Ângulo

O ângulo em uma produção de cinema permite ao telespectador interagir com a cena. $\mathrm{O}$ foco dado a imagens ou a personagens específicos em uma cena, podem levar o telespectador a se sentir parte da obra fílmica. Além disso, a evolução tecnológica das filmadoras proporciona atualmente uma nova visão da cena. Os atrasos em cenas diferentes, que nas primeiras filmagens podiam ser percebidos nitidamente, nas produções atuais não ocorrem, pois, uma mesma cena apresenta diversos ângulos e com isso diversas visões, que dependem do telespectador.

Som

O som em uma produção fílmica, também desperta diferentes sensações nos telespectadores. Sua correta adequação ao cinema acrescenta "[..] um registro descritivo uma vez que conseguimos interagir com ele prevendo acontecimentos e sentindo sensações que ele nos proporciona" (CARRERA, 2012, p. 41). Quando se assiste um filme no qual há interação com a cena, mesmo que inconscientemente, o som proporciona sensações de pertencimento ao filme. A 
cena e o som ficam atrelados de tal forma, que é possível lembrar de uma a cena, quando se ouve a música que foi utilizada no filme em outros locais, como rádio, TV, internet, etc. Para Carrera, (2012) é possível criar uma ambientação de um filme muito mais prazerosa e envolvente com o som, do que apenas com a imagem.

\section{Edição}

Nas palavras de Carrera (2012, p. 41), "é a edição quem rege a organização dos elementos fílmicos visuais e sonoros, agrupando ou justapondo-os e delimitando seu período de duração". Assim sendo, a edição de um filme está intrinsicamente ligada a forma como este será interpretado. "A Edição é, portanto, um processo de articulação das possibilidades narrativas e expressivas da obra, e suas bases estão presentes em todas as fases de criação" (CALANSAS; LEE, 2008, p. 24). Neste sentido, uma boa edição deve unir a sequência fílmica com os elementos sonoros e visuais que a compõem, propiciando aos telespectadores um envolvimento com a obra.

Além destes elementos, podemos elencar outros diversos da composição fílmica, como: o corte das cenas, o cenário, bem como outros elementos constituintes. São estes os elementos que compõe uma sequência fílmica e que devem ser considerados pelo professor, quando for utilizar as produções cinematográficas em sala de aula. É preciso por parte destes, estarem cientes destes elementos constituintes e ter subsídios que propiciem aos aprendizes elementos mínimos para a leitura audiovisual.

Os elementos necessários para a leitura de imagens ou de filmes ou qualquer outra mídia não precisam estar nos conteúdos curriculares estruturantes obrigatórios, mas sim na pedagogia do professor em entender estes elementos e fazer os alunos lê-los. Para entender a influência dos meios de comunicação e das mídias de massa que se enquadram o cinema, na sociedade atual, é necessária uma renovação das metodologias de ensino consideradas relevantes e dos recursos utilizados. O cinema apresenta estas características, ao proporcionar sensações diversificadas aos seus espectadores que o transportam para um mundo imaginário capaz de influenciar em sua atuação no mundo real.

\section{CONSIDERAÇÕES FINAIS}

Ao final da exposição realizada, é possível tecer considerações que corroboram com a discussão apresentada, e ilustram a influência das TDIC no ensino. Essa representatividade das TDIC se afirma quando pensamos em um Ensino de Ciências não apenas como produto científico, mas também e fundamentalmente como um produto social, atrelado a cultura e a tecnologia. Um mesmo ensino que se engendra em vivências sociais, construído com/pela/sociedade, embora tenha-se uma visão de que Ciência e Ensino de Ciências é produto exclusivo de laboratórios especializados.

Enquanto produto social enfatiza-se que as realidades socioculturais em que os aprendizes estão inseridos devem levar a comunidade escolar a repensar suas práticas e incentivar modos mais adequados de promoção do saber, partindo-se 
daquilo que tem significância para os estudantes, aquilo em que eles experenciam em seu cotidiano.

Nesse viés, acrescenta-se a enormidade de informações variadas que a sociedade recebe, desde uma simples embalagem até informações mais complexas e ricas em informações subjetivas. Dentre essas informações, encontram-se aquelas recebidas pela visão, que são as de maior apelo, por ser a experiência sensorial primeira com qualquer objeto. Nesta premissa, vê-se a necessidade de incorporá-la ao ensino, para que tais informações não fiquem apenas no encantamento mais levem o observador a vê-la enquanto forma de aprendizagem. A essas informações visuais, presentes no cotidiano, é dado o nome de linguagem visual, e assim como a escrita, precisa ser interpretada.

Junto da linguagem visual, estão as informações que unem imagem e som, permitindo um contato sinestésico com o objeto observado. A esta combinação de informações é dada o nome de linguagem audiovisual, e foi esta a linguagem foco deste estudo.

Ao unir imagem e som, os filmes, sendo eles produto pedagógico, feito sob uma abordagem didática e com foco direto para a sala de aula, ou fruto mercadológico, usando os conceitos científicos em seu enredo apenas para entreter o telespectador, sua composição propicia um envolvimento com a produção, produzindo um tipo de recepção unificada de informações, facilitando a abstração da mensagem que se quer transmitir por meio dessas produções fílmicas.

Quando o cinema chegou ao Brasil, sua potencialidade logo foi percebida, e apropriada para o ensino, por setores sociais que viam nestas produções um modo profícuo de promover o conhecimento, por estes fazerem parte do cotidiano dos alunos, fora das paredes escolares, mas em suas experiências diárias. Isso pode ser afirmado, também, pelos documentos oficiais que norteiam o ensino, que enfatizam a necessidade de recursos didáticos diversificados para a promoção do conhecimento, e dentre estes, cita-se os filmes enquanto linguagem.

Este estudo não objetivou e não se deteve em ilustrar os métodos construtivos de uma produção fílmica e apontar que estes devem estar presentes nos conteúdos curriculares obrigatórios estruturantes para a educação básica. Mas apontou caminhos para o professor, que o possam levar a perceber que esses mesmos métodos construtivos apresentam características que facilitam a leitura de uma obra fílmica, e devem estar presentes em sua pedagogia, quando objetivarem sensibilizar os alunos para o conhecimento, tendo filmes como objeto mediador. 


\title{
Cinema as a language in science teaching
}

\begin{abstract}
Thinking about the teaching of science not only as a scientific product, but also and fundamentally, as a socio cultural product, this work aimed to present a reflection on the use of cinema as a language in Science Teaching. For this, it presents historically the formative process of the sciences as curricular discipline of basic education, as well as approaching the science teaching of the cinematographic language, which denominates of audiovisual language. In order to facilitate the process of reading a film, in the course of this work, we highlight the need for audiovisual literacy, both in cognitive terms and in technical terms of the methods used in the composition of a film. As initial results, emphasis is placed on the need to use this type of resource in the classroom, considering that they are part of the daily life of the student and should not be overlooked. However, this study did not stop to illustrate the constructive methods of a film production, but to point out ways for the teacher, that lead him to realize that these same constructive methods present characteristics that facilitate the reading of a film work, and must be present in their pedagogy, when they aim to sensitize students to knowledge, having films as mediator object.
\end{abstract}

KEY WORDS: Science Teaching. Movies. Audiovisual Language. 
NOTA

1. Peso, em alfabetização visual, é entendido como aquilo que atrai o olhar do observador em primazia.

\section{REFERÊNCIAS}

ALENCAR, S. E. P. O cinema na sala de aula: uma aprendizagem dialógica da disciplina história. 2007. 156 f. Dissertação (Mestrado em Educação) Universidade Federal do Ceará, Fortaleza, 2007.

ALTOÉ, A.; SILVA, H. O Desenvolvimento Histórico das Novas Tecnologias e seu Emprego na Educação. In: ALTOÉ, A.; COSTA, M. L. F.; TERUYA, T. K. Educação e Novas Tecnologias. Maringá: Eduem, 2005, p 13-25.

ARAÚJO, I. Prefácio. In: COSTA, A. Compreender o Cinema. Rio de Janeiro: Globo, 1987.

ARROIO, A.; GIORDAN, M. O vídeo educativo: aspectos da organização do ensino. Química Nova na Escola, n. 24, nov. 2006.

BORBA, E. M. B. O uso de filmes como recurso pedagógico no estudo das epidemias: possibilidades na aprendizagem significativa. 2015. 90 f. Dissertação (Programa de Pós-Graduação em Formação Científica, Educacional e Tecnológica) - Universidade Tecnológica Federal do Paraná, Curitiba, 2015.

BRASIL. Lei no 9.394, de 20 de dezembro de 1996. Estabelece as diretrizes e bases da educação nacional. Diário Oficial da União, Brasília, 23 dez. 1996a. Disponível em: < http://www. planalto.gov.br/ccivil 03/LEIS/19394.htm >. Acesso em 20 jul. 2017.

BRASIL. Ministério da Educação e do Desporto. Secretaria de Educação Média e Tecnológica. Parâmetros Curriculares Nacionais - PCNs/PCN+ Ensino Médio: orientações educacionais complementares aos Parâmetros Curriculares Nacionais. Brasília: MEC/ SEMTEC, 2002, v. 2.

CALASANS, P.; LEE, T. Edição e finalização em multimídia digital. V. 1. Palhoça: Unisul virtual, 2008.

CARRERA, V. M. Contribuições do uso do cinema para o ensino de ciências: tendências entre 1997 e 2009. 2012. 125 f. Dissertação (Programa de PósGraduação em Educação) - Faculdade de Educação, Universidade de São Paulo, São Paulo, 2012. 
CARVALHO, R. I. B. de. Universidade Midiatizada: o uso da televisão e do cinema na Educação Superior. Brasília: Ed. SENAC-DF, 2007.

CHAVES, E. O. C. A tecnologia e a educação. Revista de Educação, v.3, n. 7, p.2943, 1999. Disponível em: < http://www.periódicos.puccampinas.edu.br/ser/index.php/reveducacao > Acesso em 27 jul. 2017.

CYSNEIROS, P. G. Interação, tecnologias e educação. Recife: UFPE, 2010. Disponível em: <http://www.nre.seed.gov.br/ibaiti/arquivos/File/Cysneiros.pdf>. Acesso em 27 jul. 2017.

DONDIS, D. Sintaxe da Linguagem Visual. São Paulo: Martins Fontes, 2003.

DUARTE, R. Cinema \& Educação. Belo Horizonte: Autêntica, 2009.

FARIA, A. C. M. et al. "A ciência que a gente vê no cinema": uma intervenção escolar sobre o papel da ciência no cotidiano. Revista Brasileira de Pesquisa em Educação em Ciências, v. 15, n. 3, p. 645-659, 2015.

FREIRE-MAIA, N. A ciência por dentro. 6 ed. Petrópolis: Vozes, 2000.

FRESQUET, A. M. Cinema e educação: a lei 13006. Reflexões, perspectivas e propostas. 1. ed. Ouro Preto: Universo, v. 1, 2015, 216p.

KENSKI, V. M. Educação e comunicação: interconexões e convergências. Educ. Soc., Campinas, vol. 29, n. 104 - Especial, p. 647-665, out. 2008. Disponível em: <http://www.cedes.unicamp.br>. Acesso em: 01 set. 2017.

Tecnologias e ensino presencial e a distância. Campinas: Papirus, 2003.

LEITE, M. Desenho Infantil: Questões Práticas e Polêmicas. In Infância e Produção Cultural (KRAMER, S; LEITE, M. Orgs.) Campinas: Papirus, 1998.

LENCASTRE, J. A.; CHAVES, J. H. A imagem como linguagem. In: Libro de actas do IX Congreso Internacional Galego-Portugués de Psicopedagogia. Universidade da Coruña, 2007. p. 1162-1173.

MEGID NETO, J. O que sabemos sobre a pesquisa em ensino de ciências no nível fundamental: tendências de teses e dissertações defendidas entre 1972 e 1995. 
In: II ENCONTRO NACIONAL DE PESQUISA EM EDUCAÇAO E CIÊNCIAS, Valinhos, 1999.

MUNDO EDUCAÇÃO. Pré-História. Disponível em:

$<$ http://mundoeducacao.bol.uol.com.br/historiageral/prehistoria.htm $>$. Acesso em: 04 set. 2017.

NAPOLITANO, M. Como usar o cinema na sala de aula. São Paulo: Contexto, 2003.

PARANÁ. Secretaria de Estado da Educação do Paraná. Diretrizes Curriculares da Educação Básica - Ciências. Curitiba: SEED/DEB, 2008. Disponível em:

$<$ http://www.educadores.diaadia.pr.gov.br/arquivos/File/diretrizes/dce cien.pdf>. Acesso em: 20 jul. 2017.

PIMENTA, M. A. A. As mídias na escola: comunicação e aprendizado. São Paulo: S.N., 1995.

REIS JUNIOR, J. A. O livro de imagens luminosas. Jonathas Serrano e a gênese da cinematografia educativa no Brasil (1889-1937). 2008. $251 \mathrm{f}$. Tese (Doutorado em Educação) -Pontifícia Universidade Católica do Rio de Janeiro, Rio de Janeiro, 2008.

RODRIGUES, C. O cinema e a produção. 3. ed. Rio de Janeiro: Lamparina editora, 2010.

SANTOS, J. N. O ensino-aprendizagem de ciências naturais na educação básica: o filme como recurso didático nas aulas de ecologia. 2013. 272 f. Dissertação (Mestrado em Formação Científica, Educacional e Tecnológica) - Universidade Tecnológica Federal do Paraná, Curitiba, 2013.

SETTON, M. G. J. Cinema: instrumento reflexivo e pedagógico. In: SETTON, M. da G. J. (Org.). A cultura da mídia na escola: ensaios sobre cinema e educação. São Paulo: Annablume, 2004, p. 67-80.

SILVA, T. Os filmes infantis e a aprendizagem de Ciências na sala de aula. In: SANTOS, L. H. S. (Org.). Biologia Dentro e Fora da Escola - Meio Ambiente, Estudos Culturais e Outras Questões. Porto Alegre: Mediação, 2000, p. 55-68.

SOUSA, C. G. A linguagem cinematográfica na constituição do sentido na obra 
THIEL, G. C.; THIEL, J. C. Movie takes, a magia do cinema na sala de aula. Curitiba: Aymará, 2009.

TRIVELATO, S. F.; SILVA, R. L. F. Ensino de Ciências. São Paulo: Ed Cengage Learning, 2011.

VALENTE, J. A. A comunicação e a educação baseada no uso das tecnologias digitais de informação e comunicação. UNIFESO-Humanas e Sociais, v. 1, n. 01, p. 141-166, 2014.

VAZ, A.; ANDRADE, A. F.; SIQUEIRA, P. H. A importância da alfabetização visual nas diferentes áreas do conhecimento. GRAPHICA 2009, p. 595-609, 2009.

Recebido: 23 jan. 2018

Aprovado: 19 jul. 2018

DOI: $10.3895 /$ actio.v3n2.7672

Como citar:

BUENO, A. J. A., SILVA, S. L. R. O cinema como linguagem no ensino de ciências. ACTIO, Curitiba, v. 3, n. 2, p. 154-172, mai./ago. 2018. Disponível em: <https://periodicos.utfpr.edu.br/actio>. Acesso em: XXX Correspondência:

Alcione José Alves Bueno

Av. General Carlos Cavalcanti, 4748 - CEP 84030-900, Uvaranas - Ponta Grossa-PR - Brasil

Direito autoral: Este artigo está licenciado sob os termos da Licença Creative Commons-Atribuição 4.0

Internacional

(c) (i) 